\section{OPEN ACCESS}

Edited by:

Qiaobao Zhang

Xiamen University, China

Reviewed by:

Jinhu Yang,

Tongji University, China

Yunxiao Wang,

Institute for Superconducting and

Electronic Materials, Australia

Hui Xia,

Nanjing University of Science and

Technology, China

*Correspondence:

Chenghao Yang

esyangc@scut.edu.cn

Specialty section:

This article was submitted to Physical Chemistry and Chemical

Physics,

a section of the journal

Frontiers in Chemistry

Received: 30 January 2018 Accepted: 08 March 2018

Published: 26 April 2018

Citation:

Xiong J, Pan Q, Zheng F, Xiong X, Yang C, Hu D and Huang C (2018) N/S Co-doped Carbon Derived From Cotton as High Performance Anode

Materials for Lithium Ion Batteries.

Front. Chem. 6:78.

doi: 10.3389/fchem.2018.00078

\title{
N/S Co-doped Carbon Derived From Cotton as High Performance Anode Materials for Lithium Ion Batteries
}

\author{
Jiawen Xiong ${ }^{1}$, Qichang Pan ${ }^{1}$, Fenghua Zheng ${ }^{1}$, Xunhui Xiong ${ }^{1}$, Chenghao Yang ${ }^{1,2 *}$, \\ Dongli $\mathrm{Hu}^{3}$ and Chunlai Huang ${ }^{3}$ \\ ${ }^{1}$ Guangzhou Key Laboratory for Surface Chemistry of Energy Materials, New Energy Research Institute, School of \\ Environment and Energy, South China University of Technology, Guangzhou, China, ${ }^{2}$ Guangdong Engineering and \\ Technology Research Center for Surface Chemistry of Energy Materials, New Energy Research Institute, School of \\ Environment and Energy, South China University of Technology, Guangzhou, China, ${ }^{3}$ Jiangsu Key Lab of Silicon Based \\ Electronic Materials, Jiangsu GCL Silicon Material Technology Development Co., Ltd, Xuzhou, China
}

Highly porous carbon with large surface areas is prepared using cotton as carbon sources which derived from discard cotton balls. Subsequently, the sulfur-nitrogen co-doped carbon was obtained by heat treatment the carbon in presence of thiourea and evaluated as Lithium-ion batteries anode. Benefiting from the S, N co-doping, the obtained S, N co-doped carbon exhibits excellent electrochemical performance. As a result, the as-prepared $\mathrm{S}, \mathrm{N}$ co-doped carbon can deliver a high reversible capacity of $1,101.1 \mathrm{~mA} \mathrm{~h} \mathrm{~g}^{-1}$ after 150 cycles at $0.2 \mathrm{~A} \mathrm{~g}^{-1}$, and a high capacity of $531.2 \mathrm{~mA} \mathrm{~h}$ $\mathrm{g}^{-1}$ can be observed even after 5,000 cycles at $10.0 \mathrm{~A} \mathrm{~g}^{-1}$. Moreover, excellently rate capability also can be observed, a high capacity of $689 \mathrm{~mA} \mathrm{~h} \mathrm{~g}^{-1}$ can be obtained at $5.0 \mathrm{~A} \mathrm{~g}^{-1}$. This superior lithium storage performance of $\mathrm{S}, \mathrm{N}$ co-doped carbon make it as a promising low-cost and sustainable anode for high performance lithium ion batteries.

Keywords: lithium-ion batteries, anode materials, sustainable, cotton, N/S co-doped carbon

\section{INTRODUCTION}

In the past decade, lithium-ion batteries (LIBs) have been widely used as power sources for computing, communications, consumer batteries (3C battery), and electric vehicle. And LIBs with a wide range of applications which due to its have high working voltage, high energy density, and long service life (Goodenough and Kim, 2010; Goodenough and Park, 2013; Zheng et al., 2015). Currently, graphite is mostly used as anode material for commercial LIBs due to its good electronic conductivity, low cost and outstanding cycling stability. However, graphite can not meet the increased energy and power density of high performance LIBs due to the low specific capacity and poor rate performance (Huang et al., 2016; Wang et al., 2017; Pan et al., 2018). On the other hand, the low lithiation/de-lithiation potentials $\left(<0.3 \mathrm{~V} \mathrm{vs.} \mathrm{Li}^{+} / \mathrm{Li}\right)$ which resulting in seriously security issue (Guo et al., 2011). Therefore, it is necessary to develop novel anode materials to replace graphite anode for high-performance LIBs (Pan et al., 2017a).

Recently, amorphous carbon and hard carbon are attracted attentions as promising anode to replace graphite anode for LIBs, which due to these carbonaceous materials exhibit higher specific capacity and offer higher lithiation/de-lithiation potential (Wang et al., 2009; Casas and Li, 2012; Tang et al., 2012). Moreover, these carbonaceous materials with partially graphitic carbons which can accommodate $\mathrm{Li}^{+}$in the disordered interlayers as well as in the micropores, and can exhibit excellent cycling stability and rate capability (Wu et al., 2003). On the other 
hand, other carbonaceous materials such as carbon nanotube, graphene and fullerenes were also developed as anode for LIBs, and exhibit excellent electrochemical performance (Etacheri et al., 2015; Wang et al., 2015). However, in order to synthesize these carbonaceous materials which rely on hydrocarbon precursors, resulting in expensive cost and commercially nonviable. Therefore, it is necessary to explore a scalable and inexpensive precursor as carbon sources for these carbonaceous materials as anode materials for LIBs.

Nowadays, multitudinous biomass raw materials have been extensively used as precursor for carbonaceous materials and application in LIBs. So many biomass raw materials attracted attention such as peanut (Ding et al., 2015), ramie (Jiang et al., 2016), sisal (Yu et al., 2015), bamboo (Jiang et al., 2014), green tea leaves (Han et al., 2014), peat moss (Ding et al., 2013), rice husk (Wang et al., 2013), banana peel (Lotfabad et al., 2014), and so on. However, cotton attracted more attention and have been considered as the most promising compared with the other biomass materials due to its abundant and low cost. On the other hand, in China, cotton is planted around 550 Million tons per year and giant cotton-products are abandoned which from clothes, medical alcohol cotton, and so on. Moreover, lots of abandoned cotton-products will bring lots of problems, such as environmental pollution, safe question, and so on.

Herein, we addressed the above mentioned issues by prepared high performance carbon-based anode materials using cotton as precursor, as shown in Figure 1. Highly porous carbon with large surface areas were prepared from cotton via s sample method. And the N/S-coped carbon were further obtained using thiourea as nitrogen and sulfur sources. When evaluated as anode materials for LIBs, these carbon materials exhibit outstanding rate capability and long-term cycling stability.

\section{EXPERIMENTAL}

\section{Material Preparation}

$1.5 \mathrm{~g}$ cotton was dipped in homogeneous $\mathrm{Mg}\left(\mathrm{NO}_{3}\right)_{2}$ solution $\left(8 \mathrm{~mol} \mathrm{~L}^{-1}, 20 \mathrm{ml}\right)$, then dried in the oven. After that, the obtained cotton were annealed at $800^{\circ} \mathrm{C}$ under $\mathrm{N}_{2}$ atmosphere for $3 \mathrm{~h}$ with a heating rate of $5^{\circ} \mathrm{C} \mathrm{min}^{-1}$. After cooling, the obtained cotton carbon (denoted as CC) were washed with $1 \mathrm{M} \mathrm{HCl}$ and distilled water several times, respectively, then dried in the oven.

To obtained the N, S co-doped carbon, the obtained CC were immersed in $100 \mathrm{ml}$ thiourea solution with ratio of 10:1. After drying, the obtained powders were calcined at $800^{\circ} \mathrm{C}$ under $\mathrm{N}_{2}$ atmosphere for $3 \mathrm{~h}$. The $\mathrm{N}, \mathrm{S}$ co-doped cotton carbon (denoted as NS-CC) powders were obtained after cooling.

\section{Material Characterizations}

The XRD patterns of all samples were conducted on the Bruker D8 Advance (Germany) (Cu, $\mathrm{K} \alpha, \lambda=1.5405 \AA$ ). Raman spectra were obtained on a JOBIN-Yvon HR800 Raman spectrometer. Morphology of the all samples were studied by SEM (FEI Quanta 200 FEG) and TEM (Tecnai G2 F20 S-TWIN, Japan). BET method and non-linear density functional theory (NLDFT) (ASAP 2020 Micromeritics) were applied to test the specific surface area and the pore size distribution.

\section{Electrochemical Measurements}

The samples were executed in CR2025 coin cells. The mingled ratio of sample CC, sample NS-CC and carbon black and poly (vinylidenedifluoride) were 7:2:1 (the loaded active electrode materials are about $0.5 \mathrm{mg} \mathrm{cm}^{-2}$ ). The mixture was coating on copper foil to prepare electrodes. Metal lithium boil as counter electrode and $1 \mathrm{M} \mathrm{LiPF}_{6}$ dissolved in ethylene carbonate (EC) and dimethyl carbonate (DMC) $(1: 1, \mathrm{v} / \mathrm{v})$ as electrolyte. CV and EIS were conducted on a CHI660A electrochemical workstation. Galvanostatic charge/discharge and cycling performance were executed at $25^{\circ} \mathrm{C}$ based on the active electrode material corresponding specific capacity.

\section{RESULTS AND DISCUSSIONS}

The morphology of the all samples was characterized by SEM firstly. Figures 2A,C exhibit the SEM images of cotton carbon, which shows micron size bulk materials and composed of nanosheets. Figures 2B-D shows the SEM images of the cotton carbon after $\mathrm{N}$ and $\mathrm{S}$ co-doped, which exhibits similar morphology to cotton carbon. Moreover, cotton carbon and S, $\mathrm{N}$ co-doped cotton carbon with a large number of pores in the nanosheets according to the HRSEM (Figures 2C,D). On the other hand, EDS element mapping of $\mathrm{S}, \mathrm{N}$ co-doped cotton carbon were investigated, which indicated that $\mathrm{C}, \mathrm{N}, \mathrm{O}$, and $\mathrm{S}$ elements exist $\mathrm{S}, \mathrm{N}$ co-doped cotton carbon. Furthermore, $\mathrm{S}$ and $\mathrm{N}$ elements evenly distributed (Figures 2G-J) in the carbon matrix. Therefore, the results indicated that the $\mathrm{N}$ and $\mathrm{S}$ elements were successfully doped into cotton carbon after heat treatment the carbon in presence of thiourea. The microstructure of CC and NS-CC was further studied by TEM, and the results are shown in Figures 2E,F. It clearly illustrates that the samples are amorphous carbon with nano/meso porous structure (Chen et al., 2014). Furthermore, typical selected area electron diffraction further proved that the carbon were amorphous, which corresponding to TEM results (Zhu and Akiyama, 2016).

The XRD patterns of the CC and NSCC are showed in Figure 3A. There are no obvious peaks for magnesium compounds in CC sample, which indicated that the $\mathrm{Mg}\left(\mathrm{NO}_{3}\right)_{2}$ or $\mathrm{MgO}$ are removed completely by washed with dilute hydrochloric acid. And two broad peaks at around 23 and $43^{\circ}$ can be observed both at CC and NS-CC samples, which can be attributed to (002) and (100) graphitic planes, respectively (Hou et al., 2015; Chen et al., 2017). The Raman spectra of the CC and NSCC are shown in Figure 3B, two peaks at around 1,361 and $1,596 \mathrm{~cm}^{-1}$ were obtained, which corresponding to the $\mathrm{D}$ band and G band for carbon materials, respectively (Li et al., 2015; Gao et al., 2017). Furthermore, the D band arises from edges, defects, and disordered carbon, whereas the $\mathrm{G}$ band is ascribed to $\mathrm{sp}^{2}$ hybridized carbon (Pan et al., 2017b). Therefore, a high $\mathrm{I}_{\mathrm{D}} / \mathrm{I}_{\mathrm{G}}$ band intensity ratio indicates the generation of large amounts of defects. The $\mathrm{I}_{\mathrm{D}} / \mathrm{I}_{\mathrm{G}}$ ratio for NS-CC is higher than that of $\mathrm{CC}$, which indicated that more vacancies and defects generated by doping $\mathrm{N}$ and $\mathrm{S}$ atoms into the carbon material. More importantly, more vacancies and defects are beneficial for the transmission of Li-ion and offer more active site for Li storage, 

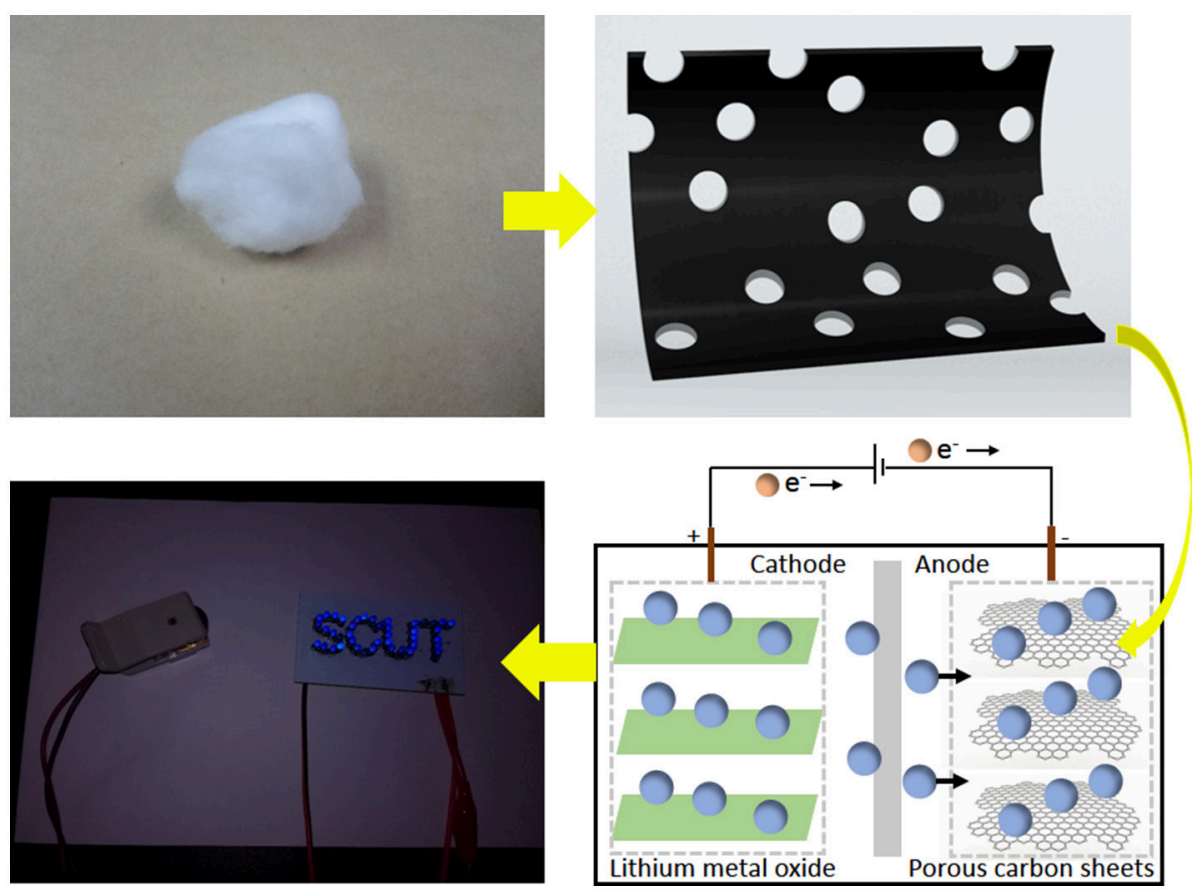

FIGURE 1 | Schematic of the fabrication of porous carbon sheet anode form wasted cotton for Lithium-ion battery anode powering blue light emitting diode (LED).

which resulting in improved electrochemical performance (Qie et al., 2015; Lu et al., 2017).

The XPS measurement was conducted to confirmed that the presence of $\mathrm{N}$ and $\mathrm{S}$ elements in NS-CC. As shown in Figures S1A,B, the survey spectrum for NS-CC and CC exhibit two predominant peak at around 284.8 and $532 \mathrm{eV}$ can be observed, which can be assigned to $\mathrm{C}$ and $\mathrm{O}$. It certified for the NS-CC that N and S atoms were successfully doped corresponding with EDS element mapping. In Figures S1C,D, the C 1s XPS spectrum for both CC and NS-CC can be deconvoluted into five peaks, which corresponding to $\mathrm{C}=\mathrm{C}, \mathrm{C}-\mathrm{C} / \mathrm{C}=\mathrm{N}, \mathrm{C}$ $\mathrm{O}, \mathrm{C}=\mathrm{O}$ and $\pi-\pi^{*}$ (Liu et al., 2017), respectively. The high resolution $\mathrm{N}$ 1s spectrum as shown in Figure 3E, the $\mathrm{N}$ 1s speak can be fitted by three component peaks at around 401.9, 400.5, and $398.3 \mathrm{eV}$, which can be ascribed to graphitic $\mathrm{N}$, pyrrolic $\mathrm{N}$ and pyridinic N, respectively (Ou et al., 2015). As for high resolution of $S 2 p$ spectrum (Figure $3 F$ ), there were five peaks attributed to $-\mathrm{C}-\mathrm{S}-\mathrm{C}$ - bond and $-\mathrm{C}-\mathrm{SO}_{\mathrm{X}}-\mathrm{C}$ - bond. Therefore, these results indicated that the $\mathrm{N}$ and $\mathrm{S}$ has been successfully incorporated into the carbon structure of NS-CC. And the content of N and $\mathrm{S}$ in NS-CC were confirmed for 3.0 and $1.4 \%$, respectively. The heteroatoms $\mathrm{N}$ and $\mathrm{S}$ can effectively enlarge the interlayer space because of their lager radius than $\mathrm{C}$ atom, resulting in forming the defects and providing more active sites for Li-ions on the carbon materials (Xu et al., 2015, 2016; Xiong et al., 2016). Moreover, pyridinic $\mathrm{N}$ and quaternary $\mathrm{N}$ are favorable for $\mathrm{Li}^{+}$and electrons and the doped $\mathrm{S}$ in the carbon materials can participate in the redox reactions contribute to the reversible capacity (Ma et al., 2018).

The nitrogen adsorption/desorption isotherms and the pore size distribution of CC and NS-CC are shown in Figures 3C,D.
As shown in Figure 3C both of the two samples showed type IV isotherms (Islam et al., 2017). The BET specific surface area of CC and NS-CC are 1235.35 and $1326.20 \mathrm{~m}^{2} \mathrm{~g}^{-1}$, respectively. The BET specific surface areas of NS-CC increased compare than the $\mathrm{CC}$ after $\mathrm{N}$ and $\mathrm{S}$ atoms doping. In addition, the highly porous structure of the two samples were further evaluated by Barrett-Joyner-Halenda (BJH) calculations (Figure 3D). It can be seen that the two samples exhibit a broad pore size distribution, and the pore size of the two samples were centered at around 2 and $5 \mathrm{~nm}$, respectively. Therefore, NS-CC exhibits larger specific surface area which can provide more active sites for lithium ion storage. Moreover, the highly porous structure of the two samples can greatly shorten the diffusion distance of both electrons and ions, which resulting in improved rate performance (Hao et al., 2014).

The electrochemical performance of CC and NS-CC was first measured by cyclic voltammetry $(\mathrm{CV})$ with voltage range of 3.0$0.01 \mathrm{~V}$. Figure $4 \mathrm{~A}$ exhibits the CV curves of the NS-CC sample. During the first discharge cycle, three cathodic peaks at around 1.4 and $0.65 \mathrm{~V}$ can be obtained and disappeared in the subsequent cycles, which corresponding to formation of a solid-electrolyte interphase (SEI) film (Wang et al., 2011; Jiang et al., 2013) as well as some irreversible and side reactions associated with the decomposition of electrolyte (Yoshio et al., 2000). Moreover, the CV profiles almost overlapped after the initial scanning cycle, which indicates that the structural stability of the NS-CC electrode during the subsequently cycling. On the other hand, the CV curves of CC electrode (Figure S2A) are similar to the NS-CC electrode.

The charge and discharge profiles of CC and NS-CC electrode at $0.1 \mathrm{~A} \mathrm{~g} \mathrm{~g}^{-1}$ with cutoff voltage window of $0.01-3.0 \mathrm{~V}$ were 

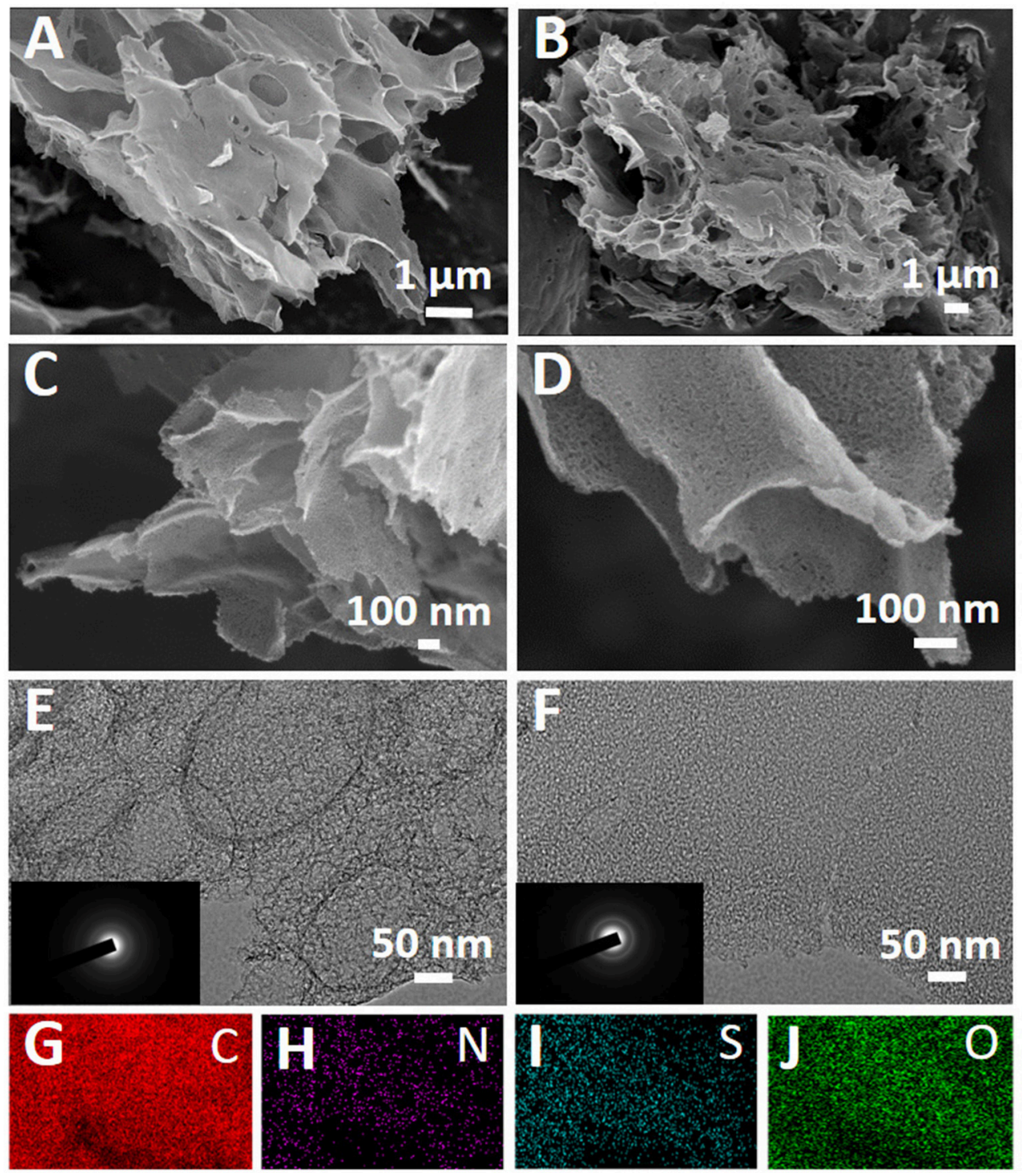

FIGURE 2 | SEM images of (A,C) CC and NS-CC (B,D); TEM images of (E) CC and (F) NS-CC (the inset of part is the SAED pattern); (G-J) EDS mapping of NS-CC.

studied. As shown in Figure 4B and Figure S2B, two plateaus at around 1.4 and $0.65 \mathrm{~V}$ can be observed during the first discharge process, which corresponding to the forming of SEI layer and decomposition of the electrolyte, in good agreement with the above CV results. The first discharge capacity of CC and NS-CC are as high as 3,275.1 and 4,179.1 $\mathrm{mA} \mathrm{h}^{-1}$, while the initial reversible capacity are only $1,512.3$ and $1,823.3 \mathrm{~mA} \mathrm{~h}$ $\mathrm{g}^{-1}$, corresponding to low initial Coulombic efficiency of 46.2 and $43.6 \%$, respectively. The large irreversible capacity loss for the CC and NS-CC electrode can be ascribed to formation of a SEI layer on the relatively large specific surface area (Jiang et al., 2013). Furthermore, a mass of reduction of oxygen functionalities on the carbon materials surface (Bhattacharjya et al., 2014) and reduction of electrolyte components on the active electrode of the CC and NS-CC electrode (Hu et al., 2007) also contributed to the irreversible capacity loss.
The cycling performance of the CC and NS-CC electrode were evaluated at $0.2 \mathrm{~A} \mathrm{~g}^{-1}$ (Figure 4D). NS-CC electrode exhibits excellent cycling stability and a high reversible capacity of $1101.1 \mathrm{~mA} \mathrm{~h} \mathrm{~g}^{-1}$ can be observed after 150 cycles, but for CC electrode, a lower reversible capacity of $637.1 \mathrm{~mA} \mathrm{~h} \mathrm{~g}^{-1}$ can be obtained. Rate performance is very important for LIBs, especially application in electric vehicles. Therefore, the rate performance of the samples were evaluated at various current densities from 0.1 to $5.0 \mathrm{~A} \mathrm{~g} \mathrm{~g}^{-1}$. As seen in Figure 4C, NS-CC electrode can deliver reversible capacities of $1,443,1,035,954,884,802$, and $689 \mathrm{~mA} \mathrm{~h} \mathrm{~g}^{-1}$ at $0.1,0.2,0.5,1.0,2.0$, and $5.0 \mathrm{~A} \mathrm{~g}^{-1}$, respectively. In contrast, the reversible capacities are 1,020, 655, 541, 478, 427, and $370 \mathrm{~mA} \mathrm{~h} \mathrm{~g}^{-1}$ at $0.1,0.2,0.5,1.0,2.0$, and $5.0 \mathrm{~A} \mathrm{~g}^{-1}$ for CC electrode. Obviously, the NS-CC electrode exhibits excellent rate capability. Therefore, the long-term cycling at high current density was also tested for NS-CC electrode, the results as shown 

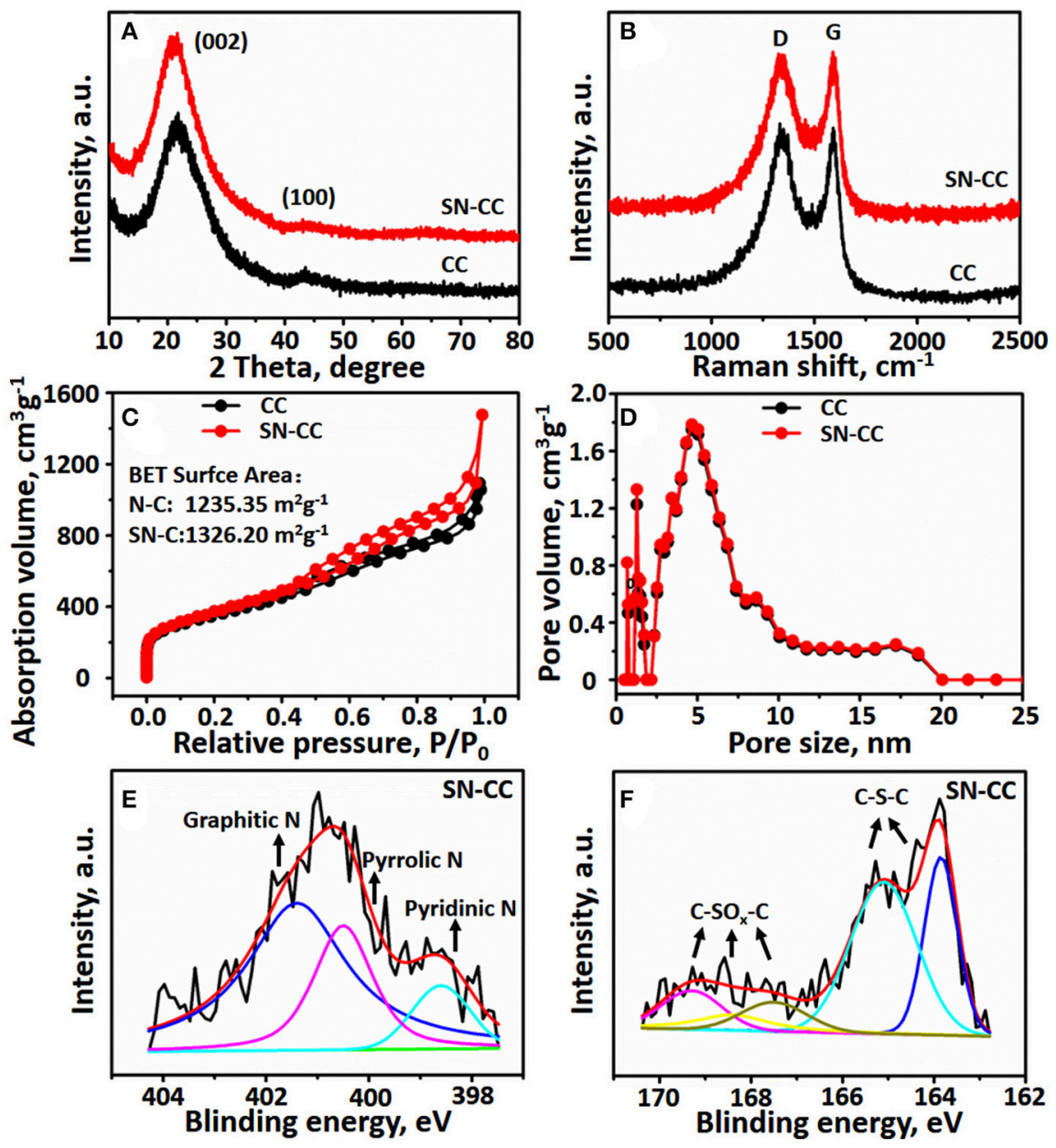

FIGURE 3 | (A) XRD patterns (B) Raman spectrum (C) Nitrogen adsorption/desorption isotherm (D) Pore size distribution of CC and NS-CC. High-resolution scans of (E) N spectrum (F) S2p spectrum electrons of NS-CC.

in Figure 4E. NS-CC electrode can deliver a high reversible capacity of $531.2 \mathrm{~mA} \mathrm{~h} \mathrm{~g}^{-1}$ can be obtained even after 5,000 cycles at $10.0 \mathrm{~A} \mathrm{~g}^{-1}$. However, $\mathrm{CC}$ electrode only delver a lower reversible of $283 \mathrm{~mA} \mathrm{~h} \mathrm{~g}^{-1}$ after 5,000 cycles at the same current density. Therefore, NS-CC electrode exhibits excellent rate performance and long-term cycling stability, which shows better electrochemical performance than previous reported carbonbased materials, as shown in Table S1. As a result, The NSCC electrode delivered amazing electrochemical performance especially with ultrahigh specific capacity and rate capability which can be given rise to the following reasons: (1) The carbon materials interlayer spacing are expanded by $\mathrm{N}$ and $\mathrm{S}$ successfully co-doping which benefit Li-ions diffusion. (2) The marked large surface of carbon materials offer plentiful micropores and mesopores structure shorten the diffusion distance, sufficient contact between electrolyte and electrode and active sites for lithium ion storage. (3) The ample pyridinic N, pyrrolic N and -S$\mathrm{C}$-S- covalent bonds built adequate active sites to improve surface capacity contribution (Xia et al., 2017).

The electrochemical impedance spectroscopy for CC and NS-CC electrode were further investigated to understand the significantly improved electrochemical performance. As shown in Figure S3, the Nyquist plots of CC and NS-CC electrode have shown the typical characteristics of one semicircle and a sloping straight line (Liu et al., 2016). The diameter of the semicircle is reduced in the plots of the NS-CC electrode compared with that of the CC electrode, indicating the decreased charge-transfer resistance at the electrode/electrolyte interface after doping of $\mathrm{N}$, $\mathrm{S}$ atoms into the carbon. On the other hand, the charge transfer resistance presents a decreasing trend along with the cycles for both CC and NS-CC electrode, which due to formation of stable SEI film and the process of activation after cycling (Pan et al., 2016).

In order to further understand the high-rate performance, the capacitive behavior of the NS-CC and CC electrode were investigated and their kinetics were also analyzed with $\mathrm{CV}$ measurements. Figure 5A and Figure S4A show the CV curves of NS-CC electrode at various scan rates ranging from 0.1 to $10 \mathrm{mV} \mathrm{s}^{-1}$. All of the curves display a similar shape, two cathodic peaks and one anodic peak are evidently on each curve. The peak current is not proportional to the square root of the sweep rate $(v)$, indicating that the charge/discharge process is comprised of 

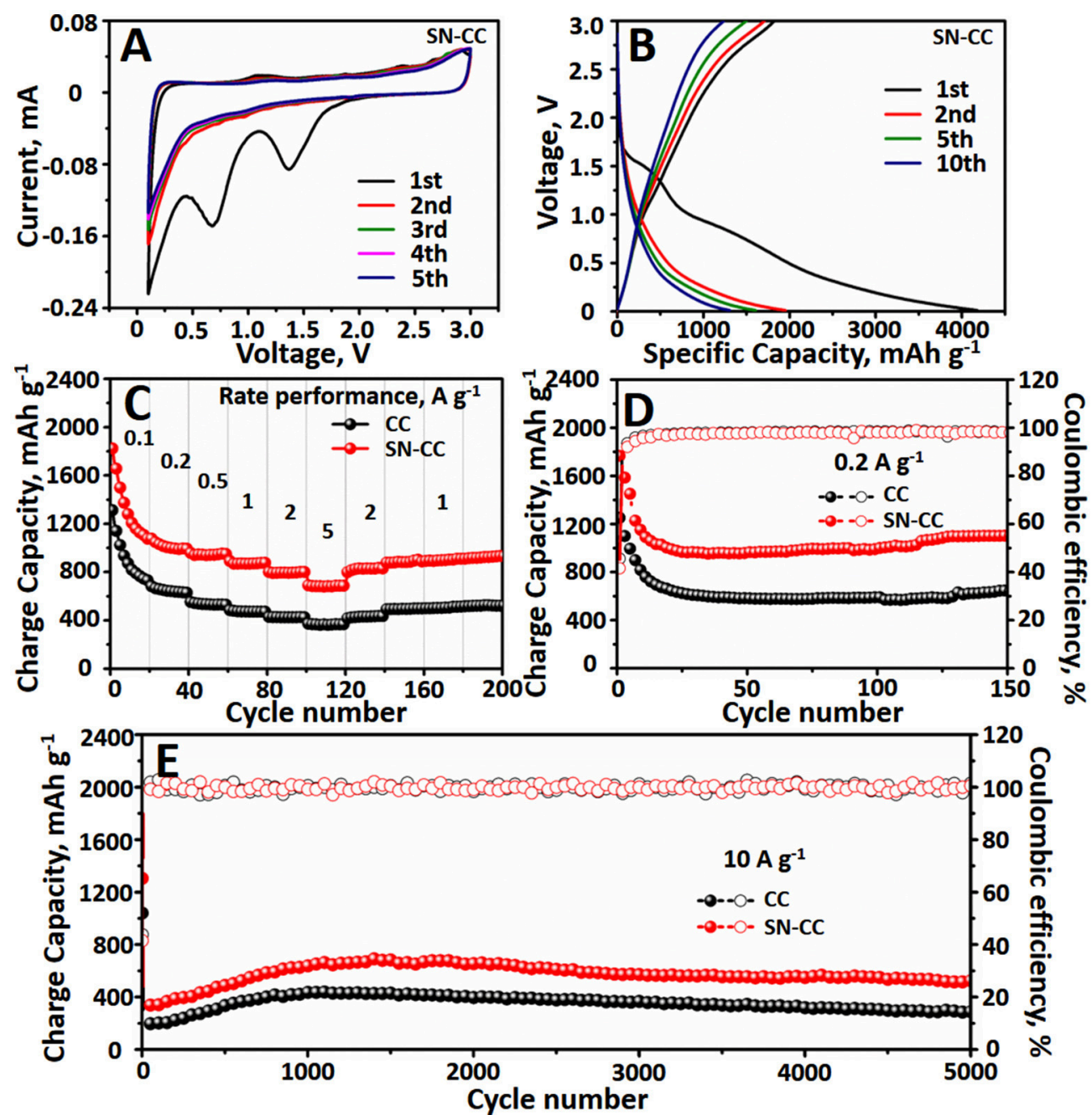

FIGURE 4 | (A) CV curves and (B) first 10 cycles of charge-discharge profiles of NS-CC; (C) Rate performance and (D) cyclic performance at $0.2 \mathrm{~A} \mathrm{~g}^{-1}$; (E) long-term cyclic performance at $10 \mathrm{~A} \mathrm{~g}^{-1}$ of CC and NS-CC.

faradic and non-faradic processes. According to the equation of the relationship of $i$ and $v$ :

$$
i=a v^{b}
$$

or

$$
\log (i)=b \times \log (v)+\log (a)^{\prime}
$$

Here, $\mathrm{a}$ and $\mathrm{b}$ are constants. The process is an ionic diffusion controlled behavior when $b$-value is equal to 0.5 , while is $\mathrm{Li}^{+}$ capacitive behavior when $b$-value is equal to 1.0. Figure $5 \mathbf{B}$ presents $\log (i)-\log (v)$ plots for NS-CC electrode on the CV curves at peak 1,2 and 3 potentials and the $b$-value are $0.84,0.75$ and 0.77 , respectively. And for $\mathrm{CC}$ the $b$-value are $0.75,0.71$, and 0.97 , respectively (Figure S4B). Therefore, It can be seen that all these values of $b$ indicate fast kinetics resulting from the pseudocapacitive effect. Moreover, To quantify the pseudocapacitive contribution, we can divide the current response $\mathrm{i}$ at a fixed potential $\mathrm{V}$ into pseudocapacitive $\left(\mathrm{k}_{1} v\right)$ and diffusion-controlled contributions $\left(\mathrm{k}_{2} v^{0.5}\right)$ by following equation (Muller et al., 2015).

$$
i(V)=k_{1} v+K_{2} v^{1 / 2}
$$

By calculating both $\mathrm{k} 1$ and $\mathrm{k} 2$ constants, the overall contribution of pseudocapacitor at various scan rates can be obtained. The detail pseudocapacitive contribution of NS-CC and CC electrode at $10 \mathrm{mV} \mathrm{s}^{-1}$ as shown in Figure 5C and Figure S4C, in which $78.9 \%$ as capacitive (red region). Therefore, all contribution ratios of the capacitive capacity at scan rates of $0.1,0.2,0.5,1,2$, and $5 \mathrm{mV} \mathrm{s}^{-1}$ were also obtained. Figure 5D and Figure S4D shows contributions of the pseudocapacitive behaviors at various scan rates. The proportion of capacitive contribution for NSCC electrode are $29.8,31.7,36.9,43.5,52.1,64.7$, and $78.9 \%$ at $0.1,0.2,0.5,1,2,5$, and $10.0 \mathrm{mV} \mathrm{s}^{-1}$, respectively. Furthermore, the contribution for CC electrode are 27.1, 28.2, 32.3, 41.3, 50.1, 62.6 , and $75.6 \%$ at $0.1,0.2,0.5,1.0,2.0,5.0$, and $10.0 \mathrm{mv} \mathrm{s}^{-1}$. As a 

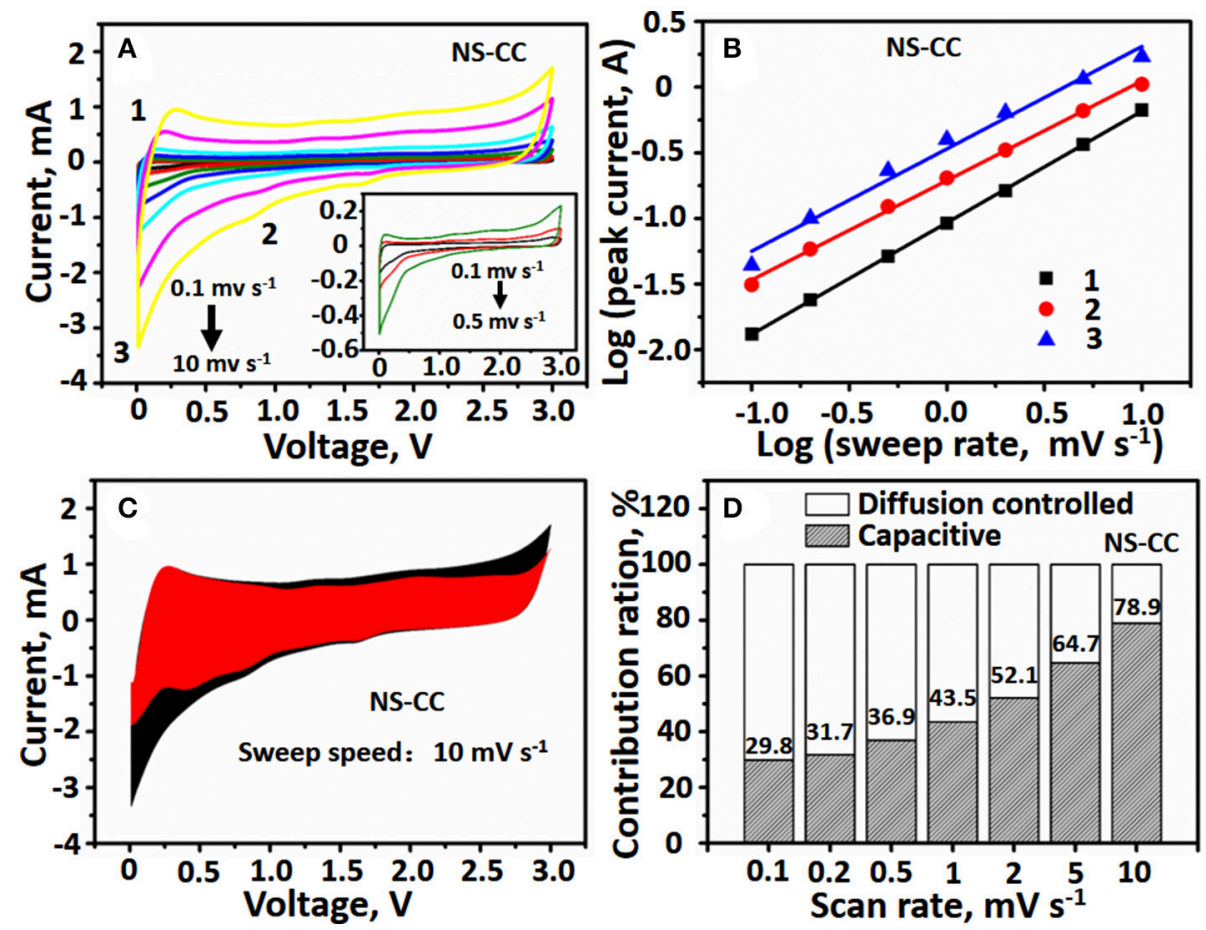

FIGURE 5 | (A) CV curves measured between 0.01 and $3.0 \mathrm{~V}$ at various scan rate from 0.1 to $10 \mathrm{mV} \mathrm{s}^{-1}$. (B) The $b$-value determined by using the relationship between peak current and scan rate. (C) CV curve with the pseudocapacitive fraction shown by red and diffusion shown by black at a scan rate of $10 \mathrm{mV} \mathrm{s}^{-1}$. (D) Bar chart showing the percentage of pseudocapacitive contribution at vs. scan of NS-CC.

result, the capacitive contribution for CC is smaller than the NSCC electrode, which can attribute to the NS-CC electrode with larger specific area after $\mathrm{N}$ and $\mathrm{S}$ atoms co-doping, resulting in enhanced pseudocapacitive contribution (Augustyn et al., 2014; Chao et al., 2016).

\section{CONCLUSION}

In summary, highly porous carbon were prepared by using cotton as precursor with a sample method. Subsequently, the sulfurnitrogen co-doped carbon were obtained via heat treatment the carbon in presence of thiourea, which can induce the defects and the expanded interlayer of the carbon. Therefore, the expanded interlayer and defects can reduce the diffusion distance of $\mathrm{Li}$ ions as well as offer more active sites for lithium storage. As a result, S, N co-doped carbon exhibits excellent electrochemical performance when evaluated as anode materials for Lithium-ion materials. The as-prepared S, N co-doped carbon can deliver a high reversible capacity of $546.4 \mathrm{~mA} \mathrm{~h} \mathrm{~g}^{-1}$ even after 5,000 cycles at $10 \mathrm{~A} \mathrm{~g}^{-1}$. Moreover, excellently rate capability also can be observed, a high capacity of $600 \mathrm{~mA} \mathrm{~h} \mathrm{~g}^{-1}$ can be obtained at $5.0 \mathrm{~A} \mathrm{~g}^{-1}$. This superior lithium storage performance of $\mathrm{S}, \mathrm{N}$ codoped carbon make it as a promising low-cost and sustainable anode material for lithium ion batteries.

\section{AUTHOR CONTRIBUTIONS}

JX conducted the experiments CY is the supervisor of this research work. JX and QP helped writing. JX, FZ, XX, DH, and $\mathrm{CH}$ performed the characterization and data analysis. All authors involved the analysis of experimental data and manuscript preparation.

\section{ACKNOWLEDGMENTS}

We gratefully acknowledge the financial support from the Science and Technology Planning Project of Guangdong Province, China (No. 2017B090916002), Guangdong Natural Science Funds for Distinguished Young Scholar (2016A030306010), Guangdong Innovative and Entrepreneurial Research Team Program (2014ZT05N200) and Fundamental Research Funds for Central Universities, China (2017 ZX010).

\section{SUPPLEMENTARY MATERIAL}

The Supplementary Material for this article can be found online at: https://www.frontiersin.org/articles/10.3389/fchem. 2018.00078/full\#supplementary-material 


\section{REFERENCES}

Augustyn, V., Simon, P., and Dunn, B. (2014). Pseudocapacitive oxide materials for high-rate electrochemical energy storage. Energy Environ. Sci. 7, 1597-1614. doi: $10.1039 /$ c3ee44164d

Bhattacharjya, D., Park, H. Y., Kim, M. S., Choi, H. S., Inamdar, S. N., and Yu, J. S. (2014). Nitrogen-doped carbon nanoparticles by flame synthesis as anode material for rechargeable lithium-ion batteries. Langmuir 30, 318-324. doi: 10.1021/la403366e

Casas, C., and Li, W. (2012). A review of application of carbon nanotubes for lithium ion battery anode material. J. Power Sources 208, 74-85. doi: 10.1016/j.jpowsour.2012.02.013

Chao, D., Liang, P., Chen, Z., Bai, L., Shen, H., Liu, X., et al. (2016). Pseudocapacitive Na-Ion storage boosts high rate and areal capacity of self-branched 2D layered metal chalcogenide nanoarrays. ACS Nano. 10, 10211-10219. doi: 10.1021/acsnano.6b05566

Chen,Y., Wang, M., Tian, M., Zhu,Y. Z., Wei, X. J., Jiang, T. et al. (2017). An innovative electro-fenton degradation system self-powered by triboelectric nanogenerator using biomass-derived carbon materials as cathode catalyst. Nano Energy 42, 314-321. doi: 10.1016/j.nanoen.2017.10.060

Chen, L., Zhang, Y., Lin, C., Yang, W., Meng, Y., Guo, Y., et al. (2014). Hierarchically porous nitrogen-rich carbon derived from wheat straw as an ultra-high-rate anode for lithium ion batteries. J. Mater. Chem. A 2, 9684-9690. doi: 10.1039/C4TA00501E

Ding, J., Wang, H., Li, Z., Cui, K., Karpuzov, D., Tan, X., et al. (2015). Peanut shell hybrid sodium ion capacitor with extreme energy-power rivals lithium ion capacitors. Energy Environ. Sci. 8, 941-955. doi: 10.1039/C4EE02986K

Ding, J., Wang, H., Li, Z., Kohandehghan, A., Cui, K., and Xu, Z. (2013). Carbon nanosheet frameworks derived from peat moss as high performance sodium ion battery anodes. ACS Nano. 7, 11004-11015. doi: 10.1021/nn404640c

Etacheri, V., Hong, C. N., and Pol, V. G. (2015). Upcycling of packing-peanuts into carbon microsheet anodes for lithium-ion batteries. Environ. Sci. Technol. 49, 11191-11198. doi: 10.1021/acs.est.5b01896

Gao, S., Chen, Y., Su, J., Wang, M., Wei, X., Jiang, T., et al. (2017). Triboelectric nanogenerator powered electrochemical degradation of organic pollutant using pt-free carbon materials. ACS Nano. 11, 3965-3972. doi: $10.1021 /$ acsnano.7b00422

Goodenough, J. B., and Kim, Y. (2010). Challenges for rechargeable li batteries, chem. Mate 22, 587-603. doi: $10.1021 / \mathrm{cm} 901452 \mathrm{z}$

Goodenough, J. B., and Park, K. S. (2013). The Li-ion rechargeable battery: a perspective. J. Am. Chem. Soc. 135, 1167-1176. doi: 10.1021/ja3091438

Guo, B., Wang, X., Fulvio, P. F., Chi, M., Mahurin, S. M., Sun, X. G., et al. (2011). Soft-templated mesoporous carbon-carbon nanotube composites for high performance lithium-ion batteries. Adv. Mater. Weinheim. 23, 4661-4666. doi: $10.1002 /$ adma. 201102032

Han, S. W., Jung, D. W., Jeong, J. H., and Oh, E. S. (2014). Effect of pyrolysis temperature on carbon obtained from green tea biomass for superior lithium ion battery anodes. Chem. Eng. J. 254, 597-604. doi: 10.1016/j.cej.2014.06.021

Hao, P., Zhao, Z., Tian, J., Li, H., Sang, Y., Yu, G., et al. (2014). Hierarchical porous carbon aerogel derived from bagasse for high performance supercapacitor electrode. Nanoscale 6, 12120-12129. doi: 10.1039/C4NR03574G

Hou, H., Banks,C. E., Jing, M., Zhang,Y., and Ji, X. (2015). Carbon quantum dots and their derivative $3 \mathrm{D}$ porous carbon frameworks for sodium-ion batteries with ultralong cycle life. Adv. Mater. Weinheim. 27, 7861-7866. doi: 10.1002/adma.201503816

Hu, Y. S., Adelhelm, P., Smarsly, B. M., Hore, S., Antonietti, M., and Maier, J. (2007). Synthesis of hierarchically porous carbon monoliths with highly ordered microstructure and their application in rechargeable lithium batteries with high-rate capability. Adv. Funct. Mater. 17, 1873-1878. doi: 10.1002/adfm.200601152

Huang,Y. G., Pan, Q. C., Wang, H. Q., Ji, C., Wu, X. M., He, Z. Q., and Li, Q. Y. (2016).Preparation of a $\mathrm{Sn} @ \mathrm{SnO}_{2} @ \mathrm{C} @ \mathrm{MoS}_{2}$ composite as a high-performance anode material for lithium-ion batteries. J. Mater. Chem. A 4, 7185-7189. doi: $10.1039 /$ C6TA02080A

Islam, M. M., Subramaniyam, C. M., Akhter, T., Faisal, S. N., and Minett, A. I. (2017). Three dimensional cellular architecture of sulfur doped graphene: selfstanding electrode for flexible supercapacitors, lithium ion and sodium ion batteries. J. Mater. Chem. A 5, 5290-5302. doi: 10.1039/C6TA10933K
Jiang, J., Luo, J., Zhu, J., Huang, X., Liu, J., and Yu, T. (2013). Diffusion-controlled evolution of core-shell nanowire arrays into integrated hybrid nanotube arrays for Li-ion batteries. Nanoscale 5, 8105-8113. doi: 10.1039/c3nr01786a

Jiang, J., Zhu, J., Ai, W., Fan, Z., Shen, X., Zou, C., et al. (2014). Evolution of disposable bamboo chopsticks into uniform carbon fibers: a smart strategy to fabricate sustainable anodes for Li-ion batteries. Energy Environ. Sci. 7, 2670-2679. doi: 10.1039/C4EE00602J

Jiang, Q., Zhang, Z., Yin, S., Guo, Z., Wang, S., and Feng, C. (2016). Biomass carbon micro/nano-structures derived from ramie fibers and corncobs as anode materials for lithium-ion and sodium-ion batteries. Appl. Surf. Sci. 379, 73-82. doi: 10.1016/j.apsusc.2016.03.204

Li, Q. Y., Pan, Q. C., Yang, G. H., Lin, X. L., Yan, Z. X., Wang, H. Q., et al. (2015). Synthesis of $\mathrm{Sn} / \mathrm{MoS}_{2} / \mathrm{C}$ composites as high performance anodes for lithiumion batteries. J. Mater. Chem. A 3, 20375-20381. doi: 10.1039/C5TA05011A

Liu, P., Li, Y., Hu, Y. S., Li, H., Chen, L., and Huang, X. (2016). A waste biomass derived hard carbon as a high-performance anode material for sodium-ion batteries. J. Mater. Chem. A 4, 13046-13052. doi: 10.1039/C6TA04877C

Liu, Z., Zhao, Z., Wang, Y., Dou, S., Yan, D., Liu, D., et al. (2017). In situ exfoliated, edge-rich, oxygen-functionalized graphene from carbon fibers for oxygen electrocatalysis. Adv. Mater. Weinheim. 29:1606207. doi: 10.1002/adma.201606207

Lotfabad, E. M., Ding, J., Cui, K., Kohandehghan, A., and Kalisvaart, W. P. (2014). High-density sodium and lithium ion battery anodes from banana peels. ACS Nano. 8, 7115-7129. doi: 10.1021/nn502045y

Lu, H., Chen, R., Hu, Y., Wang, X., Wang, Y., Ma, L., et al. (2017). Bottom-up synthesis of nitrogen-doped porous carbon scaffolds for lithium and sodium storage. Nanoscale 9, 1972-1977. doi: 10.1039/C6NR08296C

Ma, Y., Guo, Q., Yang, M., Wang, Y., Chen, T., Chen, Q., et al. (2018). Highly doped graphene with multi-dopants for high-capacity and ultrastable sodium-ion batteries. Energy Storage Mater. 13, 134-141. doi: 10.1016/j.ensm.2018.01.005

Muller, G. A., Cook, J. B., Kim, H. S., Tolbert, S. H., and Dunn, B. (2015). High performance pseudocapacitor based on 2D layered metal chalcogenide nanocrystals. Nano Lett. 15, 1911-1917. doi: 10.1021/nl504764m

Ou, J., Zhang, Y., Chen, L., Zhao, Q., Meng, Y., Guo, Y., et al. (2015). Nitrogen-rich porous carbon derived from biomass as a high performance anode material for lithium ion batteries. J. Mater. Chem. A 3, 6534-6541. doi: 10.1039/C4TA06614F

Pan, Q. C., Huang, Y. G., Wang, H. Q., Yang, G. H., Wang, L. C., Chen, J., et al. (2016). $\mathrm{MoS}_{2} / \mathrm{C}$ nanosheets encapsulated $\mathrm{Sn} @ \mathrm{SnO}_{\mathrm{x}}$ nanoparticles as high-performance Lithium-iom battery anode material. Electrochim. Acta 197, 50-57. doi: 10.1016/j.electacta.2016.03.051

Pan, Q. C., Zheng, F. H., Ou, X., Yang, C. H., Xiong, X. H., and Liu, M. L. (2017a). $\mathrm{MoS}_{2}$ encapsulated $\mathrm{SnO}_{2}$-SnS/C nanosheets as a high performance anode material for lithium ion batteries. Chem. Eng. J. 316, 393-400. doi: 10.1016/j.cej.2017.01.111

Pan, Q. C., Zheng, F. H., Ou, X., Yang, C. H., Xiong, X. H., Tang, Z. H., et al. (2017b). $\mathrm{MoS}_{2}$ decorated $\mathrm{Fe}_{3} \mathrm{O}_{4} / \mathrm{Fe}_{1-\mathrm{x}} \mathrm{S} @ \mathrm{C}$ nanosheets as high-performance anode materials for lithium ion and sodium ion batteries. ACS Sustainable Chem. Eng. 5, 4739-4745. doi: 10.1021/acssuschemeng.7b00119

Pan, Q. C., Zheng, F. H., Wu, Y. N., Ou, X., Yang, C. H., Xiong, X. H., et al. (2018). $\mathrm{MoS}_{2}$-covered SnS nanosheets as anode material for lithium-ion batteries with high capacity and long cycle life. J. Mater. Chem. A 6, 592-598. doi: $10.1039 /$ C7TA08346G

Qie, L., Chen, W., Xiong, X., Hu, C., Zou, F., Hu, P., et al. (2015). Sulfur-doped carbon with enlarged interlayer distance as a high-performance anode material for sodium-ion batteries. Adv. Sci. 2:1500195. doi: 10.1002/advs.201500195

Tang, K., Fu, L., White, R. J., Yu, L., Titirici, M. M., Antonietti, M., et al. (2012). Hollow carbon nanospheres with superior rate capability for sodiumbased batteries. Adv. Energy Mater. 2, 873-877. doi: 10.1002/aenm.2011 00691

Wang, B., Chen, J. S., Wu, H. B., Wang, Z., and Lou, X. W. (2011). Quasiemulsiontemplated formation of alpha- $\mathrm{Fe}_{2} \mathrm{O}_{3}$ hollow spheres with enhanced lithium storage properties. J. Am. Chem. Soc. 133, 17146-17148. doi: 10.1021/ja208346s

Wang, G., Shen, X., Yao, J., and Park, J. (2009). Graphene nanosheets for enhanced lithium storage in lithium ion batteries, Carbon N. Y. 47, 2049-2053. doi: 10.1016/j.carbon.2009.03.053

Wang, H. Q., Pan, Q. C., Wu, Q., Zhang, X. H., Huang, Y. G., Lushington, A., et al. (2017). Ultrasmall $\mathrm{MoS}_{2}$ embedded in carbon nanosheetscoated $\mathrm{Sn} / \mathrm{SnO} \mathrm{X}_{\mathrm{x}}$ 
as anode material for high-rate and long life Li-ion batteries. J. Mater. Chem. A 5, 4576-4582. doi: 10.1039/C6TA10932B

Wang, H. Q., Yang, G. H., Cui, L. S., Li, Z. S., Yan, Z. X., Zhang, X. H., et al. (2015). Controlled synthesis of three-dimensional interconnected graphene-like nanosheets from graphite microspheres as high-performance anodes for lithium-ion batteries. J. Mater. Chem. A 3, 21298-21307. doi: 10.1039/C5TA04882F

Wang, L., Schnepp, Z., and Titirici, M. M. (2013). Rice husk-derived carbon anodes for lithium ion batteries. J. Mater. Chem. A 1, 5269-5273. doi: $10.1039 / \mathrm{c} 3$ ta10650k

Wu, Y. P., Rahm, E., and Holze, R. (2003). Carbon anode materials for lithium ion batteries. J. Power Sources 114, 228-236. doi: 10.1016/S0378-7753(02)0 0596-7

Xia, Q., Yang, H., Wang, M., Yang, M., Guo, Q., Wan, L., et al. (2017). High energy and high power lithium-ion capacitors based on boron and nitrogen dualdoped 3D carbon nanofibers as both cathode and anode. Adv. Energy Mater. 7:1701336. doi: 10.1002/aenm.201701336

Xiong, X., Wang, G., Lin, Y., Wang, Y., Ou, X., Zheng, F., et al. (2016). Enhancing sodium ion battery performance by strongly binding nanostructured $\mathrm{Sb}_{2} \mathrm{~S}_{3}$ on Sulfur-doped graphene sheets. ACS Nano. 10, 10953-10959. doi: 10.1021/acsnano.6b05653

Xu, D., Chen, C., Xie, J., Zhang, B., Miao, L., Cai, J., et al. (2016). A hierarchical N/S-codoped carbon anode fabricated facilely from cellulose/polyaniline microspheres for high-performance Sodium-Ion batteries. Adv. Energy Mate. 6:1501929. doi: 10.1002/aenm.201501929

Xu, G., Han, J., Ding, B., Nie, P., Pan, J., Dou, H., et al. (2015). Biomassderived porous carbon materials with sulfur and nitrogen dual-doping for energy storage. Green Chem. 17, 1668-1674. doi: 10.1039/C4GC0 $2185 \mathrm{~A}$
Yoshio, M., Wang, H., Fukuda, K., Hara, Y., and Adachi, Y. (2000). Effect of carbon coating on electrochemical performance of treated natural graphite as Lithium-Ion battery anode material. J. Electrochem. Soc. 147, 1245-1250. doi: $10.1149 / 1.1393344$

Yu, X., Zhang, K., Tian, N., Qin, A., Liao, L., Du, R., et al. (2015). Biomass carbon derived from sisal fiber as anode material for lithium-ion batteries. Mater. Lett. 142, 193-196. doi: 10.1016/j.matlet.2014.11.160

Zheng, F., Yang, C., Xiong, X., Xiong, J., Hu, R., Chen, Y., et al. (2015). Nanoscale surface modification of lithium-rich Layered-Oxide composite cathodes for suppressing voltage fade. Angew. Chem. Int. Ed. 54, 13058-13062. doi: 10.1002/anie.201506408

Zhu, C., and Akiyama, T. (2016). Cotton derived porous carbon via an MgO template method for high performance lithium ion battery anodes. Green Chem. 18, 2106-2114. doi: 10.1039/C5GC02397A

Conflict of Interest Statement: $\mathrm{DH}$ and $\mathrm{CH}$ were employed by company Jiangsu Key Lab of Silicon Based Electronic Materials.

The other authors declare that the research was conducted in the absence of any commercial or financial relationships that could be construed as a potential conflict of interest.

Copyright (C) 2018 Xiong, Pan, Zheng, Xiong, Yang, Hu and Huang. This is an open-access article distributed under the terms of the Creative Commons Attribution License (CC BY). The use, distribution or reproduction in other forums is permitted, provided the original author(s) and the copyright owner are credited and that the original publication in this journal is cited, in accordance with accepted academic practice. No use, distribution or reproduction is permitted which does not comply with these terms. 